\title{
Characteristics of Patients Who Received Chemotherapy During the Covid 19 Pandemic and Changes in Oncology Practice
}

\section{Covid 19 Pandemi Döneminde Kemoterapi Alan Hastaların Özellikleri ve Onkoloji Pratiğinde ki Değişiklikler}

\author{
Yusuf Açıkgöz', Yakup Ergün², Gökhan Uçar \\ 1 Sağlık Bilimleri Üniversitesi, Ankara Şehir Hastanesi, Tıbbi Onkoloji, Ankara \\ 2 Batman Devlet Hastanesi
}

Dergiye Ulaşma Tarihi: 19.10.2020 Dergiye Kabul Tarihi 24.12.2020: Doi:10.5505/aot.2020.78010

\section{ÖZET}

GİRIŞ ve AMAÇ: Koronavirüs hastalı̆̆ 2019 (Covid 19) pandemi şartlarında, pandemi merkezinde sorunsuz bir şekilde kemoterapi alan hastaların özelliklerinin belirlenmesi ve onkoloji pratiğinde ki değişikliklerin araştırılması amaçlanmıştır

YÖNTEM ve GEREÇLER: 01.04.2020 ile 20.05.2020 tarihleri arasında merkezimizde aktif olarak kemoterapi alan ve birbirini takip eden en az iki vizitte nötropenik ateş yada Covid 19 tanısı almayan hastaların verileri retrospektif olarak incelenmiştir. Numerik ve kategorik değişkenlerin kıyaslanması için sırasıyla Wilcoxon testi ve Mc-Nemar analizi kullanıldı. Analizler sonucunda çift yönlü p değeri raporlandı ve 0.05 'in altında ki değerler istatistiksel olarak anlamlı kabul edildi.

BULGULAR: Çalışmaya toplam 98 hasta dahil edilmiştir. Tüm grupta median takip süresi 20 gün idi (6-48). Hastaların ortanca yaşı $59(28-82)$ olup, tüm grupta $52(53 \%)$ erkek hasta ve $46(\% 47)$ kadın hasta yer almaktaydı. Birinci vizitte granülosit-koloni stimüle edici faktör (G-CSF) verilen hasta sayıs1 50 (\%51) iken, ikinci vizitte G-CSF verilen hasta sayıs1 37 (\%38) idi ( $\mathrm{p}=0.035)$. İkinci vizitte öksürük (\%8 vs \%1, p=0.039), balgam ( $\% 8$ vs $\% 0, p=0.016)$ ve halsizlik $(\% 18$ vs $\% 8, p=0.004)$ şikayetlerinin birinci vizite kıyasla daha az olduğu saptanmıştır.

TARTIŞMA ve SONUÇ: Çalışmamızda hastaların Covid 19 semptomları açısından sorgulanması ve laboratuar olarak normal limitler içerisinde kalınarak kemoterapilerinin sorunsuz bir şekilde alabildikleri saptanmıştır. Ayrıca, G-CSF kullanım oranlarının ise pandemi öncesine göre literatürde belirtilen oranlardan daha fazla olduğu saptanmıştır.

Anahtar Kelimeler: Covid 19, kanser, kemoterapi, G-CSF

\section{ABSTRACT}

INTRODUCTION: To determine the characteristics of patients who received chemotherapy in the pandemic center under (Coronavirus disease 2019) Covid 19 pandemic conditions and to investigate the changes in oncology practice.

METHODS: The data of patients receiving chemotherapy in our center between 01.04.2020 and 20.05.2020 and without neutropenic fever or Covid 19 in at least two consecutive visits were retrospectively analyzed. Wilcoxon and Mc-Nemar tests were used for comparison of numerical and categorical variables, respectively. We reported two-sided $\mathrm{p}$ value and $<0.05$ were considered statistically significant

RESULTS: A total of 98 patients were included in the study. Median follow-up time was 20 days in the whole group (6-48). The median age of the patients was 59 (28-82), and there were $52(53 \%)$ male patients and 46 $(47 \%)$ female patients. While number of patients who received granulocyte-colony-stimulating factor (G-CSF) at the first visit was $50(51 \%)$, number of patients who received G-CSF at the second visit was $37(38 \%)(\mathrm{p}=$ $0.035)$. Cough $(8 \%$ vs $1 \%, \mathrm{p}=0.039)$, sputum $(8 \%$ vs $0 \%, \mathrm{p}=0.016)$ and fatigue $(18 \%$ vs $8 \%, \mathrm{p}=0.004)$ were found to be more common in the second visit compared to the first visit.

DISCUSSION AND CONCLUSION: It was shown that patients could receive chemotherapy without any problems by examining for Covid 19 symptoms and with normal limits of laboratory. In addition, the rates of GCSF use were found to be higher than the rates in the literature compared to the pre-pandemic conditions.

Key Words: Covid 19, cancer, chemotherapy, G-CSF

\section{GíRIŞ}


Tüm dünyada ciddi bir sağlık problemi oluşturan koronavirus hastalığ 2019 (Covid19) pandemisi, 2019 yılının Aralık ayında ilk olarak Çin'in Wuhan kentinde ciddi viral pnömoni ile seyreden bir epideminin saptanmasıyla başlamıştır (1). Bu enfeksiyona neden olan patojenin zarfl bir RNA betakoronavirus 2 olduğu saptandı ve "ciddi akut solunum sendromu koronavirus 2" (SARSCov-2) olarak adlandırıldı (2). Dünya sağlık örgütü (WHO) tarafindan 11 Mart 2020 tarihinde Covid-19 ad1 ile resmi olarak pandemi ilan edildi. Ülkemizde ise ilk vaka 10 Mart 2020 tarihinde saptand.

Covid 19 hastalığının genel olarak iyi seyretmesine karşın, ileri yaş ve bazı komorbiditelerin varlığında hastalığın kötü seyrettiği bildirilmiştir. $\mathrm{Bu}$ komorbiditeler arasında özelikle hipertansiyon (HT), diabetes mellitus (DM) ve koroner arter hastalığ $(\mathrm{KAH})$ öne çıkmaktadır $(3,4) . \quad \mathrm{Bu}$ komorbiditeler haricinde, kanser hastalarında ki tedaviye bağlı gelişen yada hastalığın kendisinin neden olduğu immunsupresyon, Covid 19 hastalığının kötü seyretme ihtimalini artırmas1 nedeniyle önem arz etmektedir. Kanser hastalarında Covid 19 enfeksiyonunun seyri ile ilgili yapılmış retrospektif çalışmaların bir kısmında hastalığın kötü gidişatına dair veriler bulunmakla beraber bazı çalışmalarda ise kanser hastalığının kötü bir prognostik faktör olmadığı ile ilgili görüşler de yer almaktadır (5-8). Kanser hastaları ile ilgili bu belirsizlik ve kanserin progresif bir hastalık olması nedeniyle pandemi şartlarında kanser hastalarının yönetimi hekimler için ciddi bir zorluk teşkil etmektedir.

Kanser hastalarının pandemi şartlarında yönetimi ile ilgili olarak Amerikan Klinik Onkoloji Derneği (ASCO) ve Avrupa Medikal Onkoloji (ESMO) dernekleri tarafından çeşitli öneriler düzenlemiştir. Buna rağmen pandemi merkezlerinde takip ve tedavisi devam eden kanser hastalarının yönetimi gerek ülkemizde gerekse tüm dünyada sağlı sistemi kapasitelerinin zorlanması nedeniyle zorluk teşkil etmektedir. $\mathrm{Bu}$ nedenle kanser hastalarının yönetimi ile ilgili olarak daha çok veriye ihtiyaç duyulmaktadır.

Bu çalışmamızda, ülkemizde ki önemli pandemi merkezlerinden biri olan Ankara Şehir Hastanesi'nin Tibbi Onkoloji kliniğinde takip ve tedavisi devam eden kanser hastaları arasinda Covid 19 enfeksiyonu yada nötropenik ateş geçirmeden kemoterapi alabilen hastaların birbirini takip eden iki vizit boyunca kaydedilen demografik ve klinik özelliklerinin belirlenmesi amaçlanmıştır.

\section{MATERYAL VE METOD}

\section{Hasta özellikleri}

Ankara Şehir Hastanesi T1bbi Onkoloji kliniğinde kanser tanısı almış ve 01.04.2020 ile 20.05.2020 tarihleri arasında aktif olarak kemoterapi alan hastalar çalışmaya dahil edilmiştir. Çalışmamız Ankara Şehir Hastanesi etik kurulu tarafindan onaylanmıştır. Ayrıca, çalışmamız Covid-19 pandemi şartlarına bağlı değişkenleri de içerdiği için T.C Sağlı Bakanlığ 1 tarafından da onaylanmıştır. Çalışmaya dahil edilme kriterleri; kemoterapi polikliniğinde birbirini takip eden en az 2 vizitte görülen ve kemoterapisini sorunsuz alan hastalar dahil edilmiştir. İki vizit arasında Covid-19 (PCR yada klinik pozitifliği) saptanan yada ikinci vizite ait verisi olmayan hastalar çalışmaya dahil edilmemiştir. Çalışmada yer alan hastalar, kemoterapi polikliniğinde Covid-19 şüphesi oluşturacak semptomlar açısından sorgulanmıştır; ayrıca verilen tedaviler ve laboratuar sonuçları retrospektif olarak hasta dosyalarından ve hastane otomasyon sisteminde ki kayit dosyalarından elde edilmiştir. Hastaların yaş, cinsiyet, Eastern Cooperative Oncology Group (ECOG) performans skoru, tedavi endikasyonu, primer tümör yerleşim yeri, Covid-19 semptom sorgu sonucu, komorbid hastalık varlığı, DM varlığ1, HT varlığ 1 , biyokimya analiz sonuçları, tam kan sayımı sonuçları, granülosit-koloni stimüle edici faktör (G-CSF) kullanımı, kullanılan G-CSF etken maddesi, nötropenik ateş risk kategorisi, nötropenik ateş profilaksi tipi (primer vs sekonder), G-CSF kullanım süresi, ikinci vizitte yeni gelişen semptom varlığı, ikinci vizitte verilen G-CSF ad1-süresi, ikinci vizitte bakılan biyokimya ve tam kan sayımı sonuçlarına ait veriler kaydedilmiş ve analiz edilmiştir.

\section{İstatistiksel analiz}

İstatistiksel analizler Statistical Package for the Social Sciences Version 22.0 for Windows (SPSS Inc., Chicago, IL, USA) 
programı ile yapılmıştır. Hastaların temel klinik ve laboratuar özellikleri tanımlayıcı istatistikler ile yapılmıştır. Kategorik değişkenler "\%" ile belirtilmiştir ve numerik değişkenler ise median (minimum-maximum) olarak raporlanmıştır. İki bağımlı grup arasında ki numerik değişkenleri kıyaslanması Wilcoxon testi ile yapılmıştır, kategorik değişkenlerin kıyaslanması için Mc-Nemar analizi kullanıldı. Analizler sonucunda çift yönlü $\mathrm{p}$ değeri raporlandı ve 0.05 'in altında ki değerler istatistiksel olarak anlamlı kabul edildi.

\section{SONUÇLAR}

\section{Hasta özellikleri}

Çalıșmaya toplamda 98 hasta dahil edilmiştir. Tüm grupta median takip süresi 20 gün idi (6-48). Hastaların ortanca yaşı 59 (2882) olup, tüm grupta $52(53 \%)$ erkek hasta ve 46 (\%47) kadın hasta yer almaktaydı. Hastaların \%84'ünde ECOG skoru 0-1 idi ve ECOG skoru 2 olan hasta oran1 \%16'idi. Hastaların \%46'i adjuvan yada neoadjuvan endikasyonlarla kemoterapi alıyor iken, \%54 oranında hasta metastatik hastalık nedeniyle kemoterapi alıyordu. En s1k kanser bölgesi gastrointestinal sisteme aitti $(n=41, \% 42)$. Hastaların \%46'sinda herhangi bir komorbid hastallk mevcut olup, hipertansiyonu olanların oranı \%26 iken DM olanların oranı \%17 idi. Nötropenik ateş riski açısından hastaların $\% 32$ 'si düşük riskli grupta, $\% 58$ 'i orta riskli grupta ve \%10'u yüksek riskli grupta idi. Hastaların genel özellikleri tablo 1a'da verilmiştir.

Tablo-1a: Tüm grupta ki hastaların genel özellikleri

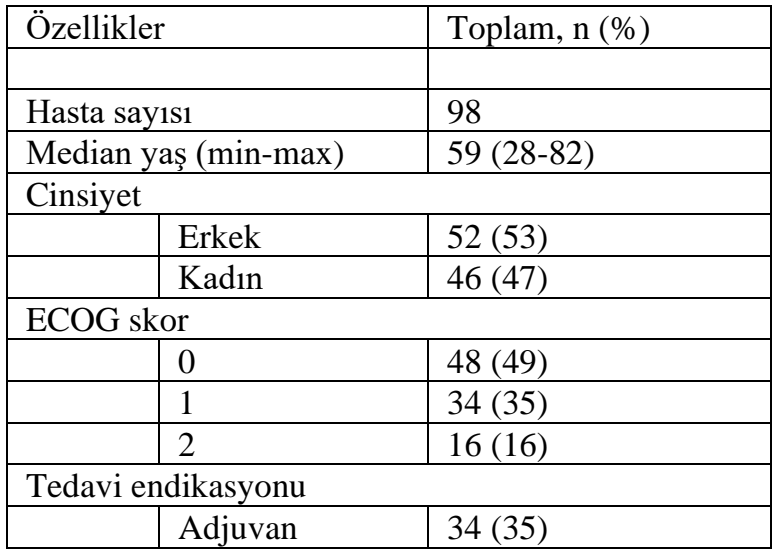

Tablo-1b: Hastaların birinci ve ikinci vizitte ki özellikleri

Adress for correspondence:(6punkto) (metne çok yakın olursa bir alta kaydırılacak e-mail:

Available at www.actaoncologicaturcica.com Copyright (Ankara Onkoloji Hastanesi

\begin{tabular}{|c|c|c|}
\hline & Neoadjuvan & $11(11)$ \\
\hline & Metastatik & $53(54)$ \\
\hline \multicolumn{3}{|c|}{ Kanser bölgesi } \\
\hline & $\begin{array}{l}\text { Gastrointestinal } \\
\text { sistem }\end{array}$ & $41(42)$ \\
\hline & $\begin{array}{l}\text { Genitüriner } \\
\text { sistem }\end{array}$ & $17(17)$ \\
\hline & Akciğer kanseri & $11(11)$ \\
\hline & Meme kanseri & $21(22)$ \\
\hline & Diğer & $8(8)$ \\
\hline \multicolumn{3}{|c|}{ Komorbid hastalık } \\
\hline & Var & $46(46)$ \\
\hline & Yok & $53(54)$ \\
\hline \multicolumn{3}{|c|}{ Hipertansiyon } \\
\hline & Var & $25(26)$ \\
\hline & Yok & $73(74)$ \\
\hline \multicolumn{3}{|c|}{ Diabetes Mellitus } \\
\hline & Var & $18(18)$ \\
\hline & Yok & $80(82)$ \\
\hline \multicolumn{3}{|c|}{ Nötropenik Ateş Riski } \\
\hline & Düşük & $31(32)$ \\
\hline & Orta & $57(58)$ \\
\hline 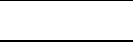 & Yüksek & $10(10)$ \\
\hline
\end{tabular}

\section{Birinci vizit}

Birinci vizitte G-CSF verilen hasta say1s1 $50(\% 51)$ idi. Bu tedavinin 19'u (\%19) primer profilaksi amaciyla verilmiş iken, 31'i (\%32) sekonder profilaksi amaciyla verildi. Hastaların 46'sına (\%47) filgrastim verilmişti, 4'üne (\%4) ise lipeg-filgrastim verilmişti. G-CSF kullanımın median süresi 3 gün (1-5) idi. Hastaların kemoterapi öncesi bakılan biyokimyasal ve tam kan sayımı parametreleri tablo $1 b^{\prime}$ de gösterilmiştir. Hastaların 2'sinde (\%2) ateş, 8'inde (8\%) öküsürük, 7'sinde (\%7) balgam, 17'sinde (\%18) halsizlik, 2'sinde (\%2) miyalji, 4'ünde (\%4) nefes darlı̆̆ 1 ve $1(\% 1)$ hastada ise tat hissinde kayıp şikayeti vardı. Hastaların birinci vizitte sorgulanan semptomları tablo 2'de gösterilmiştir. Birinci vizitte nötropenik ateş açısından yüksek riskli hastaların $(\mathrm{n}=10)$ hepsine G-CSF verilmişti, orta riskli grupta olan 57 hastadan 35'ine G-CSF verilmişti, düşük risk grubunda olan 31 hastadan ise 5'ine G-CSF verilmişti. G-CSF kullanımı ile nötropenik ateş risk grupları tablo 3'te gösterilmiştir. 


\begin{tabular}{|c|c|c|c|c|}
\hline \multirow{2}{*}{\multicolumn{2}{|c|}{ Özellikler }} & \multicolumn{2}{|c|}{ Toplam, n (\%) } & \multirow[t]{2}{*}{$p$ değeri } \\
\hline & & Birinci vizit & İkinci vizit & \\
\hline \multicolumn{5}{|c|}{ G-CSF kullanımı } \\
\hline & Var & $50(51)$ & $37(38)$ & \multirow[t]{2}{*}{$0.035^{*}$} \\
\hline & Yok & $48(49)$ & $61(62)$ & \\
\hline \multicolumn{5}{|c|}{ Profilaksi tipi } \\
\hline & Primer & $19(19)$ & 0 & \multirow[t]{2}{*}{$<0.0001 *$} \\
\hline & Sekonder & $31(32)$ & $37(38)$ & \\
\hline \multicolumn{5}{|c|}{ G-CSF türü } \\
\hline & Filgrastim & $46(47)$ & $35(36)$ & \multirow[t]{2}{*}{0.302} \\
\hline & Lipeg-filgrastim & $4(4)$ & $2(2)$ & \\
\hline \multicolumn{5}{|c|}{ Median G-CSF süresi (gün) (min-max) } \\
\hline & & $3(1-5)$ & $3(1-4)$ & 0.083 \\
\hline \multicolumn{5}{|c|}{ Median Üre düzeyi } \\
\hline & & $30.5(15-209)$ & $30.0(17-168)$ & 0.173 \\
\hline \multicolumn{5}{|c|}{ Median Kreatinin düzeyi (min-max) } \\
\hline & & $0.75(0.41-2.87)$ & $0.74(0.41-0.38)$ & 0.483 \\
\hline \multicolumn{5}{|c|}{ Median Total protein düzeyi (min-max) } \\
\hline & & $6.8(5.3-8.0)$ & $6.6(4.5-7.8)$ & $0.003 *$ \\
\hline \multicolumn{5}{|c|}{ Median Albumin düzeyi (min-max) } \\
\hline & & $4.3(2.8-4.9)$ & $4.2(2.7-5.0)$ & $0.035 *$ \\
\hline \multicolumn{5}{|c|}{ Median AST düzeyi (min-max) } \\
\hline & & $19(8.0-76.0)$ & $17(8.0-76.0)$ & 0.653 \\
\hline \multicolumn{5}{|c|}{ Median ALT düzeyi (min-max) } \\
\hline & & $23.0(7.0-170.0)$ & $22.0(8.0-156.0)$ & 0.751 \\
\hline \multicolumn{5}{|c|}{ Median ALP düzeyi (min-max) } \\
\hline & & $96(34.0-389.0)$ & $99.5(43.0-280.0)$ & 0.684 \\
\hline \multicolumn{5}{|c|}{ Median LDH düzeyi (min-max) } \\
\hline & & $192(92-699)$ & $213(83-698)$ & $0.001 *$ \\
\hline \multicolumn{5}{|c|}{ Median Total Bilirubin düzeyi (min-max) } \\
\hline & & $0.5(0.2-3.1)$ & $0.4(0.2-3.3)$ & 0.075 \\
\hline \multicolumn{5}{|c|}{ Median Direkt Bilirubin düzeyi (min-max) } \\
\hline & & $0.1(0.1-0.9)$ & $0.1(0.1-1.0)$ & 0.076 \\
\hline \multicolumn{5}{|c|}{ Median Na düzeyi (min-max) } \\
\hline & & $141(121-145)$ & $140(128-146)$ & $0.030 *$ \\
\hline \multicolumn{5}{|c|}{ Median K düzeyi (min-max) } \\
\hline & & $4.4(3.3-5.6)$ & $4.4(3.5-5.5)$ & 0.945 \\
\hline \multicolumn{5}{|c|}{ Median $\mathrm{Ca}++$ düzeyi (min-max) } \\
\hline & & $9.4(8.0-11.1)$ & $9.1(7.50-10.70)$ & $<0.001 *$ \\
\hline Median W & say1s1 (min-max) & & & \\
\hline & & $5.98(3.11-18.27)$ & $5.71(3.27-26.84)$ & 0.769 \\
\hline Median $\mathrm{Ne}$ & ay1s1 (min-max) & & & \\
\hline & & $3.56(1.92-15.61)$ & $3.61(1.04-23.50)$ & 0.866 \\
\hline Median $\mathrm{HI}$ & onsantrasyonu (mi & $\operatorname{nax})(\mathrm{g} / \mathrm{dL})$ & & \\
\hline & & $11.8(8.4-15.4)$ & $11.7(8.0-14.8)$ & $0.020^{*}$ \\
\hline Median PL & ay1s1 (min-max) & & & \\
\hline & & $286(86-842)$ & $256(113-842)$ & 0.645 \\
\hline $\begin{array}{l}\text { G-CSF:Gr } \\
\text { Aminotran } \\
\text { Nötrofil, } \mathrm{H}\end{array}$ & $\begin{array}{l}\text { losit-Koloni Stin } \\
\text { raz, , ALP: Alkal } \\
\text { Hemoglobin, PLT }\end{array}$ & $\begin{array}{l}\text { Edici Faktör, } \\
\text { Fosfataz, LDH: I } \\
\text { latelet. }\end{array}$ & $\begin{array}{l}\text { partat Aminotran } \\
\text { rogenaz, WBC: } \mathrm{B}\end{array}$ & $\begin{array}{l}\text { LT: Alani } \\
\text { Sayıs, Net }\end{array}$ \\
\hline
\end{tabular}

Tablo-2: Hastaların birinci ve ikinci vizitte ki semptom değerlendirmesi

\begin{tabular}{|l|c|c|}
\hline Semptomlar & Toplam, n (\%) & $p$ değeri \\
\hline
\end{tabular}

Adress for correspondence:(6punkto) (metne çok yakın olursa bir alta kaydırılacak 


\begin{tabular}{|c|c|c|c|c|}
\hline & & Birinci vizit & İkinci vizit & \\
\hline \multicolumn{5}{|l|}{ Ateș } \\
\hline & Var & $2(2)$ & $1(1)$ & \multirow[t]{2}{*}{1.00} \\
\hline & Yok & $96(98)$ & $97(99)$ & \\
\hline \multicolumn{5}{|l|}{ Öksürük } \\
\hline & Var & $8(8)$ & $1(1)$ & \multirow[t]{2}{*}{$0.039 *$} \\
\hline & Yok & $90(92)$ & 97 (99) & \\
\hline \multicolumn{5}{|l|}{ Balgam } \\
\hline & Var & $7(8)$ & 0 & \multirow[t]{2}{*}{$0.016^{*}$} \\
\hline & Yok & $91(92)$ & 98 & \\
\hline \multicolumn{5}{|c|}{ Halsizlik } \\
\hline & Var & $17(18)$ & $8(8)$ & \multirow[t]{2}{*}{$0.004^{*}$} \\
\hline & Yok & $81(82)$ & $90(92)$ & \\
\hline \multicolumn{5}{|l|}{ Myalji } \\
\hline & Var & $2(2)$ & $1(1)$ & \multirow[t]{2}{*}{1.00} \\
\hline & Yok & $96(98)$ & $97(99)$ & \\
\hline \multicolumn{5}{|l|}{ Dispne } \\
\hline & Var & $4(4)$ & 0 & \multirow[t]{2}{*}{0.125} \\
\hline & Yok & $94(96)$ & 98 & \\
\hline \multicolumn{5}{|l|}{ Anosmi } \\
\hline & Var & 0 & 0 & \multirow[t]{2}{*}{ N/A } \\
\hline & Yok & 98 & 98 & \\
\hline \multicolumn{5}{|c|}{ Tat kayb1 } \\
\hline & Var & $1(1)$ & 0 & \multirow[t]{2}{*}{1.00} \\
\hline & Yok & $97(99)$ & 98 & \\
\hline
\end{tabular}

Tablo-3: Nötropenik ateş risk grupları ve G-CSF kullanım oranları

\begin{tabular}{|l|l|l|}
\hline $\begin{array}{l}\text { Nötropenik } \\
\text { ateş riski }\end{array}$ & \multicolumn{2}{|l|}{ G-CSF kullanımı } \\
\hline & Var & Yok \\
\hline Yüksek risk & $10(100 \%)$ & 0 \\
\hline Orta risk & $35(61 \%)$ & $22(39 \%)$ \\
\hline Düşük risk & $5(16 \%)$ & $26(84 \%)$ \\
\hline
\end{tabular}

\section{İkinci vizit}

İkinci vizitte G-CSF verilen hasta sayıs 37 (\%38) idi. Bu tedavilerin tamamı sekonder profilaksi şeklinde verilmişti. 35 hasta (\%36) filgrastim almıştı ve 2 (\%2) hastada lipeg-filgrastim kullanılmıştı. Median G-CSF kullanım süresi 3 gün (1-4) idi. Hastaların ikinci vizitte kemoterapi öncesi bakılan biyokimyasal analizler ve tam kan sayımı sonuçları tablo 1 b'de gösterilmiştir. Hastaların 1'inde ateş, 1'inde öksürük, 8'inde halsizlik ve l'inde miyalji mevcut iken hiçbir hastada balgam, nefes darlığ1, koku ve tat kaybı yoktu. Hastaların ikinci vizitte öksürük, balgam ve halsizlik şikayeti istatistiksel olarak anlamlı bir şekilde daha az olduğu saptandı. Hastaların ikinci vizitte sorgulanan semptomları tablo 2'de gösterilmiştir. İkinci vizitte G-CSF kullanım oranı istatistiksel olarak anlamlı olarak birinci vizite göre daha düşüktü (\%51 vs \%38, p=0.035). Ayrıca, birinci vizite kıyasla hastaların median total protein, albumin, plazma $\mathrm{Na}+$ düzeyi, plazma $\mathrm{Ca}++$ düzeyi, median hemoglobin konsantrasyonu ve platelet sayıs ikinci vizitte daha düşük iken, median LDH düzeyi ikinci vizitte daha yüksek saptandı (tablo $1 \mathrm{~b}$ ).

\section{TARTIŞMA}

$\mathrm{Bu}$ çalışmamızda Covid 19 pandemi döneminde önemli bir merkez olan hastanemizin Tıbbi Onkoloji kliniğinde kemoterapilerini sorunsuz bir şekilde aldığ 1 , birbirini müteakip iki vizit ile gözlemlenen hastaların özellikleri ortaya konulmuştur. Hastaların birinci vizit ile ikinci vizit arasında ateş, myalji, dispne, koku ve tat kaybı semptomları açısından benzerlik bulunur iken, 
ikinci vizitte öksürük, balgam ve dispne şikayetleri istatistiksel olarak anlamlı oranda daha az olduğu saptanmıştır. Bu farklılığın kemoterapiye bağlı olarak primer kanser hastalığının semptomlarında ki gerileme ile ilişkili olduğunu düşünmekteyiz. Ayrıca GCSF kullanımının istatistiksel olarak anlamlı bir şekilde daha az olduğu gözlemlenmiştir. Bunun nedeni olarak ise pandemi şartlarında özellikle orta riskli grupta ki hastalarda nötropeni kaynaklı immunsupresyondan korunmak için G-CSF kullanımının ilk vizitte daha da artışı olduğunu düşünmekteyiz. G-CSF kullanımının hastane yatış süresinde azalma, nötrofil artış süresinde azalma, rölatif doz intensintesinde artışa neden olduğu pandemi öncesinde yapılmış olan çalışmalar ile gösterilmiştir $(9,10)$. Covid 19 enfeksiyonu esnasında terapötik amaçlı kullanımı ile ilgili olarak mortalitede artışa ve hastalığın kötü seyretmesine katkıda bulunduğuna dair kısitlı veri olmasına karşın henüz profilaksi amaciyla kullanımı ile ilgili olarak yeterli veri yoktur $(11,12)$. Pandeminin olmadığ 1 şartlarda GCSF kullanımı ile ilgili literatürde yapılan çalışmalar ile kıyaslandığında özellikle orta risk grubunda ki hastalarda G-CSF kullanımının literatüre göre daha fazla olduğu görülmektedir. Arnold L., ve ark yaptıkları bir populasyon bazlı kohort çalışmasında 1894 kolorektal ve akciğer kanseri hastalarının verileri incelenmiş ve nötropenik ateş açısından düşük riskli grupta G-CSF kullanım oran $\% 10 \mathrm{iken}$, orta riskli grupta ki hastalarda G-CSF kullanım oranının \%18 olduğu görülmüştür (13). Hastaların median G-CSF kullanım süresi açısından birinci ve ikinci vizitte fark olmadığ 1 saptanmıştır. Hastaların laboratuar analizlerine bakıldığında ise, kemoterapiye bağlı olarak istatistiksel olarak anlamlı derecede total protein ve albumin düzeylerinde azalma olduğu gözlenmiştir $(\mathrm{p}=0.003$ ve $\mathrm{p}=0.0035)$. Ayrıca hastaların ikinci vizitte plazma $\mathrm{Na}+$ ve $\mathrm{Ca}++$ düzeylerinin istatistiksel olarak anlamlı oranda düşük olduğu gözlenmiştir. $\mathrm{Bu}$ düşüşün kemoterapiye bağlı olarak hastalarda azalan oral alım ve plazma albümin düzeylerinde ki düşüş ile ilişkili olduğu düşünülmektedir $(p=0.030 *$ ve $p<0.001)$. Hastaların tam kan

\section{Referanslar:}

sayımı analizlerinde her iki vizitte de median WBC, Neu, Plt sayısının normal olduğu gözlenmiştir; fakat grade 1 anemi her iki vizittede saptanmıştır. Hastaların median hb düzeylerinde ikinci vizitte istatistiksel olarak anlamlı olarak düşüş olmasına rağmen grade 1 düzeyinde kalması nedeniyle kemoterapi almalarına engel oluşturmadığ 1 görülmüştür. Sonuç olarak çalışmamızda, semptomatik olarak Covid 19 enfeksiyonu ile ilgili ciddi şüphe oluşturmayan ve biyokimyasal analizleri ve tam kan sayımı sonuçları normal aralıklarda olan hastalarda primer yada sekonder profilaksi amaçlı G-CSF kullanımı ile hastalar kemoterapilerini sorunsuz bir şekilde aldıkları görülmüştür.

Kanser hastalığının dünya genelinde ciddi bir sağlık problemi olması ve sürekli bir izlem ve bazen de tedavi gerektiren bir hastalık olması nedeniyle Covid 19 pandemisi sürecinde yönetimi daha da zorluk arz etmektedir. Bununla ilgili olarak bazı kanser cerrahisi, kemoterapi ve radyoterapi tedavilerinin pandemi şartlarında düzenlenmesi ile ilgili olarak bazı otörler tarafindan çeşitli öneriler sunulmuştur (14-16). Buna rağmen henüz tüm dünyada yaygın kabul görmüş ve günlük pratikte uygulanan, kanser hastalarına özel bir Covid 19 protokolü bulunmaktadır. $\mathrm{Bu}$ konuyla ilgili daha çok prospektif ve büyük örneklem sayısı içeren çalışmalara ihtiyaç vardir.

Çalışmamızın bazı kısıtlılıkları mevcuttur. Öncelikle çalışmamızın retrospektif olması ve nispeten küçük bir hasta grubu ile kısa takip süresi en önemli kısıtlllıklarımız olduğunu düşünüyoruz. Sonuç olarak, pandemi şartlarında kanser hastalarının tedavi ve takiplerinin fayda zarar oranı gözetilerek devam ettirilmesi gerekmektedir. Bizim çalışmamızda belirttiğimiz limitler içinde kalarak hastalar takip süresince Covid 19 enfeksiyonuna yakalanmadan sorunsuz bir şekilde tedavilerini alabilmişlerdir. Kanser hastalarının Covid 19 pandemisi süresince yönetimi ile ilgili olarak daha çok veriye ihtiyaç vardır.

Çıkar çatışması: Yazarların hiçbir çıkar çatışması yoktur.

1. Phelan AL, Katz R, Gostin LO. The Novel Coronavirus Originating in Wuhan, China: 
Challenges for Global Health Governance. JAMA. 2020;323(8):709-10.

2. Lu R, Zhao $X$, Li J, Niu P, Yang B, Wu H, et al. Genomic characterisation and epidemiology of 2019 novel coronavirus: implications for virus origins and receptor binding. Lancet (London, England). 2020;395(10224):565-74.

3. Del Sole F, Farcomeni A, Loffredo L, Carnevale R, Menichelli D. Features of severe COVID-19: A systematic review and meta-analysis. 2020;50(10):e13378.

4. Ssentongo $\mathrm{P}$, Ssentongo AE. Association of cardiovascular disease and 10 other pre-existing comorbidities with COVID-19 mortality: A systematic review and meta-analysis. 2020;15(8):e0238215.

5. Liang W, Guan W, Chen R, Wang W, Li J, Xu K, et al. Cancer patients in SARS-CoV-2 infection: a nationwide analysis in China. The Lancet Oncology. 2020;21(3):335-7.

6. Wang H, Zhang L. Risk of COVID-19 for patients with cancer. The Lancet Oncology. 2020;21(4):e181.

7. Jarahzadeh MH, Asadian F, Farbod M, Meibodi B, Abbasi H, Jafari M, et al. Cancer and Coronavirus Disease (COVID-19): Comorbidity, Mechanical Ventilation, and Death Risk. J Gastrointest Cancer. 2020:1-5.

8. Cavalcanti IDL, Soares JCS. Impact of COVID-19 on cancer patients: A review. Asia-Pacific Journal of Clinical Oncology.n/a(n/a).

9. Clark OA, Lyman GH, Castro AA, Clark LG, Djulbegovic B. Colony-stimulating factors for chemotherapy-induced febrile neutropenia: a metaanalysis of randomized controlled trials. Journal of clinical oncology : official journal of the American Society of Clinical Oncology. 2005;23(18):4198-214.

10. Kuderer NM, Dale DC, Crawford J, Lyman GH. Impact of primary prophylaxis with granulocyte colony-stimulating factor on febrile neutropenia and mortality in adult cancer patients receiving chemotherapy: a systematic review. Journal of clinical oncology : official journal of the American Society of Clinical Oncology. 2007;25(21):3158-67.

11. Nawar T, Morjaria S, Kaltsas A, Patel D, PerezJohnston R, Daniyan AF, et al. Granulocyte-colony stimulating factor in COVID-19: Is it stimulating more than just the bone marrow? Am J Hematol. 2020;95(8):E210-E3.

12. Morjaria S, Zhang A, Kaltsas Md A, Parameswaran R, Patel D, Zhou W, et al. The Effect of Neutropenia and Filgrastim (G-CSF) in Cancer Patients With COVID-19 Infection. medRxiv : the preprint server for health sciences. 2020.

13. Potosky AL, Malin JL, Kim B, Chrischilles EA, Makgoeng SB, Howlader N, et al. Use of ColonyStimulating Factors With Chemotherapy: Opportunities for Cost Savings and Improved Outcomes. JNCI: Journal of the National Cancer Institute. 2011;103(12):979-82.

14. Day AT, Sher DJ, Lee RC, Truelson JM, Myers LL, Sumer BD, et al. Head and neck oncology during the COVID-19 pandemic: Reconsidering traditional treatment paradigms in light of new surgical and other multilevel risks. Oral Oncol. 2020;105:104684.

15. Tey J, Ho S, Choo BA, Ho F, Yap SP, Tuan JKL, et al. Navigating the challenges of the COVID-19 outbreak: Perspectives from the radiation oncology service in Singapore. Radiother Oncol. 2020;148:189-93.

16. Rodler S, Apfelbeck M, Stief C, Heinemann V, Casuscelli J. Lessons from the coronavirus disease 2019 pandemic: Will virtual patient management reshape uro-oncology in Germany? European journal of cancer (Oxford, England : 1990). 2020;132:13640 . 